Spatial distribution and temporal variability of arsenic in irrigated rice fields in Bangladesh: 2. Paddy soil

JESSICA DITTMAR, ANDREAS VOEGELIN, LINDA C. ROBERTS, STEPHAN J. HUG, GANESH C. SAHA, M. ASHRAF ALI, A. BORHAN M. BADRUZZAMAN, RUBEN KRETZSCHMAR

Supporting Information

(9 pages, 6 figures, 3 tables)

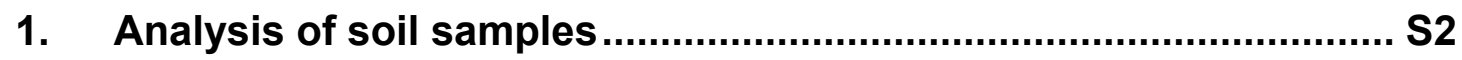

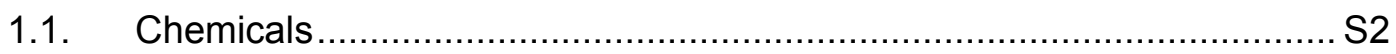

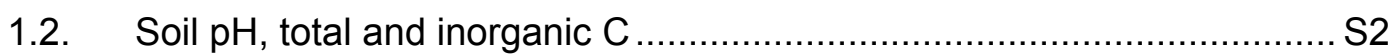

1.3. Elemental composition by XRF and method validation .........................S2

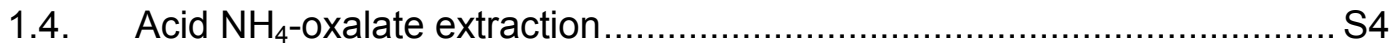

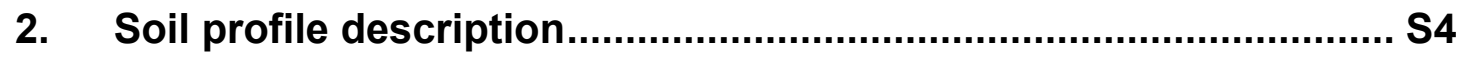

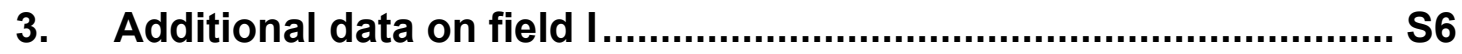

3.1. Total/oxalate extractable $\mathrm{Fe}$ and $\mathrm{pH}$ in topsoil along transect.................S6

3.2. Total As in soil versus total As in irrigation water ................................. 6

3.3. Total topsoil As concentrations at all sampling points ........................... 7

3.4. Total subsoil As and $\mathrm{P}$ along transect ........................................... 8

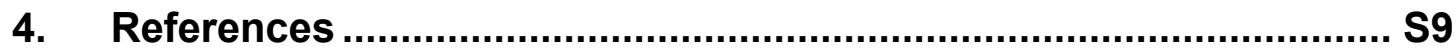




\section{Analysis of soil samples}

\subsection{Chemicals}

All reagents used were analytical grade from Merck (Germany) or Fluka (Switzerland). All solutions and standards for soil analyses were prepared with high purity $18 \mathrm{M} \Omega \mathrm{cm}$ water (Milli-Q ${ }^{\circledR}$, Millipore, USA).

\subsection{Soil $\mathrm{pH}$, total and inorganic $\mathrm{C}$}

The soil $\mathrm{pH}$ was determined in $0.01 \mathrm{M} \mathrm{CaCl}_{2} \cdot 2 \mathrm{H}_{2} \mathrm{O}$ at a solid to liquid ratio of $4 \mathrm{~g} / 10 \mathrm{~mL}$ after shaking and equilibration for 30 minutes. Total carbon content was determined in duplicates using a CHNS-analyzer (CHNS-932, LECO, Germany). Inorganic carbon content was determined in triplicates by reacting $0.2-0.5 \mathrm{~g}$ of soil in boiling $1 \mathrm{M} \mathrm{H}_{2} \mathrm{SO}_{4}$ to dissolve carbonates. The released $\mathrm{CO}_{2}$ was trapped in a column containing $\mathrm{NaOH}$ on support and determined gravimetrically.

\subsection{Elemental composition by XRF and method validation}

The elemental composition of the soil samples was analyzed by X-ray fluorescence spectrometry (XRF). Around $10 \mathrm{~g}$ of soil were milled to $<50 \mu \mathrm{m}$ in a tungsten carbide disc swing mill (Retsch ${ }^{\circledR}$ RS1, Germany). $4 \mathrm{~g}$ of soil powder were mixed with $0.9 \mathrm{~g}$ of Licowax ${ }^{\circledR}$ C Micropowder PM (Clariant, Switzerland), pressed into a 32-mm pellet and analyzed using an energy dispersive X-ray fluorescence spectrometer (SPECTRO X-LAB 2000, SPECTRO Analytical Instruments, Germany).

To validate the XRF-method for the analysis of As in soil samples, we repeatedly analyzed 3 reference materials (Table S1). The results show that the measured As contents for SS-1 and SS-2 are within the certified confidence limits. The relative standard deviation (RSD) increases with decreasing As concentration in the sample. Within the relevant concentration range, the RSD is $<7 \%$.

TABLE S1: Analyses of the reference materials LKSD-1 (CANMET MMSL, Ottawa, Canada) EnviroMAT SS-1 and SS-2 (SCP Science, Quebec, Canada) by XRF. Certified mean values and confidence limits are indicated for SS-1 and SS-2. For LKSD-1, only a provisional mean value and no confidence limits are available. $S E=$ standard error, RSD=relative standard deviation, $n=$ number of analyses.

\begin{tabular}{|c|c|c|c|c|c|c|}
\hline & \multicolumn{2}{|c|}{ Certified/Provisional value } & \multicolumn{4}{|c|}{ Measured value } \\
\hline & Mean & Confidence interval & Mean & SE & RSD & $\mathbf{n}$ \\
\hline Reference & \multicolumn{4}{|c|}{$\longrightarrow\left(\mathrm{mg} \mathrm{kg}^{-1}\right) \longrightarrow$} & $(\%)$ & \\
\hline SS-1 & 17 & $13-21$ & 19.3 & 0.31 & 6.4 & 16 \\
\hline LKSD-1 & 40 & - & 37.1 & 0.30 & 4.1 & 26 \\
\hline SS-2 & 78 & $62-94$ & 81.6 & 0.49 & 2.2 & 14 \\
\hline
\end{tabular}


In addition, a spike experiment was performed using quartz powder $\left(<0.3 \mathrm{mg} \mathrm{kg}^{-1} \mathrm{As}\right.$, $\mathrm{SiO}_{2}$, puriss p.a., Fluka, Switzerland) and soil material from the field site with low As content $\left(\sim 5.4 \mathrm{mg} \mathrm{kg}^{-1}\right.$ As) (Figure S1). Spike solutions were prepared using $\mathrm{Na}_{2} \mathrm{HAsO}_{4} \cdot 7 \mathrm{H}_{2} \mathrm{O}$. Both the quartz powder and the soil were spiked with $0,5,10,15,20$ and $25 \mathrm{mg} \mathrm{kg}^{-1}$ As. All spikes were performed in triplicates. From each sample, one pellet was prepared for XRF-analysis and was analyzed 3 times. In Figure S1, the average concentration for each spike level and the standard deviation of the 3 replicate spikes for quartz and soil are plotted versus the nominal spike level. Linear regression parameters are provided in Table S2. For both the experiment with quartz and soil, the regression slope did not significantly deviate from unity $(p=0.05)$, demonstrating the accuracy of the XRF-results. Note that the effective spike level may slightly deviate from the nominal level.

TABLE S2: Linear regression parameters (with standard error) linking the measured average As concentration $(Y)$ to the nominal spike level $(X)$. (Regression equation $Y=A+B X$, $\mathrm{df}=$ degrees of freedom).

\begin{tabular}{|l|c|c|c|c|}
\hline & A $\left(\mathbf{m g ~ k g}^{-1}\right)$ & B & df & $\mathbf{r}^{2}$ \\
\hline Quartz & $0.010( \pm 0.388)$ & $0.977( \pm 0.026)$ & 4 & 0.997 \\
\hline Soil & $5.571( \pm 0.342)$ & $1.051( \pm 0.023)$ & 4 & 0.998 \\
\hline
\end{tabular}

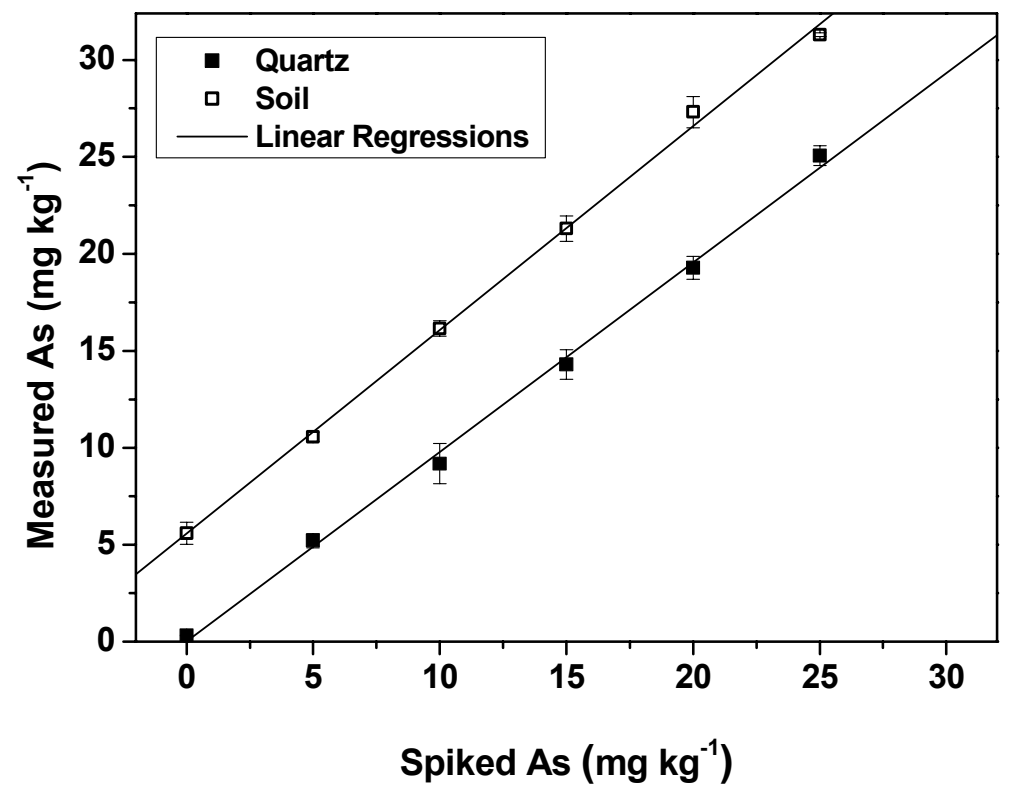

FIGURE S1: Measured As concentrations in quartz and soil spiked with 0, 5, 10, 15, 20, and $25 \mathrm{mg} \mathrm{kg}^{-1}$ As. Each spike level was prepared in triplicates. From each replicate, one pellet was analyzed 3 times by XRF. The error bars represent the standard deviation of the As concentration of the 3 replicate spikes. The As concentrations in the replicate spikes were obtained by averaging 3 repeated XRF measurements. Parameters for the linear regression lines are provided in Table S2. 


\subsection{Acid $\mathrm{NH}_{4}$-oxalate extraction}

To quantify the amount of $\mathrm{Fe}$ contained in poorly crystalline Fe-(hydr)oxides and the associated fractions of As and $\mathrm{P}$, soil samples were extracted with acid $\mathrm{NH}_{4}$-oxalate in the dark (1). Acid (pH 3.0) 0.2 $\mathrm{M} \mathrm{NH}_{4}$-oxalate was prepared from $0.2 \mathrm{M}\left(\mathrm{NH}_{4}\right)_{2} \mathrm{C}_{2} \mathrm{O}_{4} \cdot \mathrm{H}_{2} \mathrm{O}$ and 0.2 $\mathrm{M} \mathrm{C}_{2} \mathrm{H}_{2} \mathrm{O}_{4} \cdot 2 \mathrm{H}_{2} \mathrm{O}$. Subsamples of $0.5 \mathrm{~g}$ of soil were weighed into $50 \mathrm{~mL}$ centrifuge tubes and continuously agitated with $20 \mathrm{~mL}$ of acid $0.2 \mathrm{M} \mathrm{NH}_{4}$-oxalate for $4 \mathrm{~h}$ in the dark. Subsequently, the tubes were immediately centrifuged $(20 \mathrm{~min}, 1800 \mathrm{~g})$. Aliquots $(10 \mathrm{~mL})$ were filtered $(0.45 \mu \mathrm{m}$, nylon, WICOM, Germany) and acidified with $1 \% \mathrm{v} / \mathrm{v}$ of $30 \% \mathrm{HCl}$ (Suprapur $^{\circledR}$, Merck, Germany). The extracts were analyzed within one week. P and Fe were analyzed using an inductively coupled plasma-optical emission spectrometer (CCD simultaneous ICP-OES, Vista-MPX, Varian, Australia) and As using a graphite tube atomizer-Zeeman atomic absorption spectrometer (GTA-AAS, GTA120-AA240Z, Varian, USA). Fe standards were prepared from an atomic spectroscopy standard solution (Fluka, Switzerland), P standards from a phosphate standard solution (9870 Titrisol $^{\circledR}$, Merck, Germany), and As standards from $\mathrm{Na}_{2} \mathrm{HAsO}_{4} \cdot 7 \mathrm{H}_{2} \mathrm{O}$. For all elements, the RSD from triplicate extractions were $<5.5 \%$.

\section{Soil profile description}

The soil at the study site is a non-calcareous $\left(\mathrm{C}_{\text {anorg }}<0.2 \mathrm{~g} \mathrm{~kg}^{-1}\right)$ Hydragric Anthrosol (Hypereutric, Siltic) according to the World Reference Base for Soil Resources (2). The soil is mottled, varying in color between grey and red/brown with local Fe enrichments around roots, pores and on aggregate surfaces (Figure S2). The grey soil regions contain blackish Mn concretions. The soil $\mathrm{pH}$ at $>20 \mathrm{~cm}$ depth fluctuates around $\mathrm{pH} 6.8$ to 7.0. In the topsoil, cyclic $\mathrm{pH}$ variations between $\mathrm{pH} 5.6$ and 7.3 are observed, depending on sampling time and depth (Figure 5 in main part and Figure S3). The seasonal variations in topsoil pH may be influenced by input of alkalinity during irrigation and by soil ferrolysis. According to Brammer (3), ferrolysis results from the reduction of soils during monsoon flooding and their reoxidation after the water recedes and is typical for seasonally flooded Bangladesh floodplain soils. The topsoil contains around $22.8 \mathrm{~g} \mathrm{~kg}^{-1}$ organic $\mathrm{C}$ and the subsoil around 6.6 $\mathrm{g} \mathrm{kg}^{-1}$ ( $\mathrm{n}=30,10$ topsoil and subsoil samples from December 2004, May 2005 and December 2005, respectively). The higher clay content of the topsoil compared to the subsoil results from the annual intensive puddling prior to rice cultivation. The puddled topsoil is confined by a compacted plow pan at about 20-25 cm depth (Table S3). 
TABLE S3: Description of the paddy soil profile investigated in May 2005 close to the inlet of field G.

\begin{tabular}{|l|l|}
\hline Horizon & Morphological description \\
\hline Apg1 & $0-2 \mathrm{~cm}$, red-brown silt clay loam; coherent structure; consolidated \\
\hline Apg2 & $\begin{array}{l}2-25 \mathrm{~cm}, \text { grey silt clay loam with red-brown mottles around roots, pores } \\
\text { and aggregate surfaces; coherent structure; dense; many roots, from 20- } \\
25 \mathrm{~cm} \text { compacted plow pan with high density }\end{array}$ \\
\hline Bwg1 & $\begin{array}{l}25-50 \mathrm{~cm}, \text { red-brown silt loam with grey areas; aggregated, prismatic } \\
\text { structure; consolidated; some roots }\end{array}$ \\
\hline Bwg2 & $\begin{array}{l}>50 \mathrm{~cm}, \text { red-brown, diffuse yellowish mottled silt loam with grey areas; } \\
\text { coherent, slightly prismatic structure; unconstrained }\end{array}$ \\
\hline
\end{tabular}

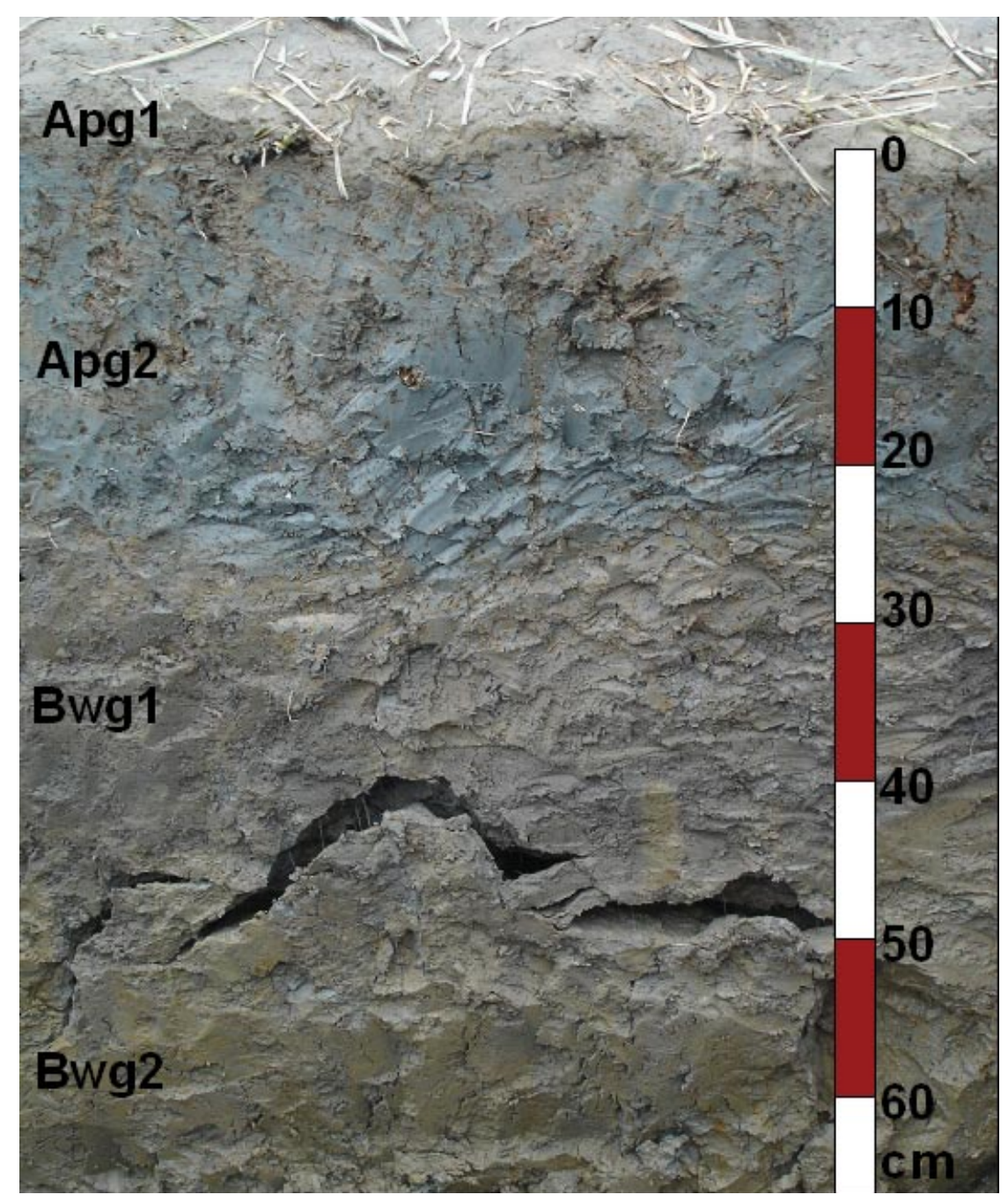

FIGURE S2: Soil profile studied in May 2005 close to the inlet of field G (see Figure 1 in the manuscript). The four labeled horizons are described in Table S3. 


\section{Additional data on field I}

\subsection{Total/oxalate extractable $\mathrm{Fe}$ and $\mathrm{pH}$ in topsoil along transect}

The total and oxalate extractable concentrations of Fe remain almost constant along the transect and over the year (Figure S3A). In Figure S3B, the soil $\mathrm{pH}$ along the transect for soil samples collected in May and December 2005 from 0-5 cm and 5-10 cm depth are shown. Over most of the transect, the soil $\mathrm{pH}$ values at 5-10 $\mathrm{cm}$ depth are between 6.1 and 6.6 and show no marked variation from May to December 2005. In May 2005, the soil $\mathrm{pH}$ at 0-5 cm depth is consistently higher than at 5-10 cm depth. In December 2005, soil $\mathrm{pH}$ at 0-5 cm depth was markedly lower than in May 2005, in agreement with the trend observed in the soil profiles (main manuscript, Figure 5D).
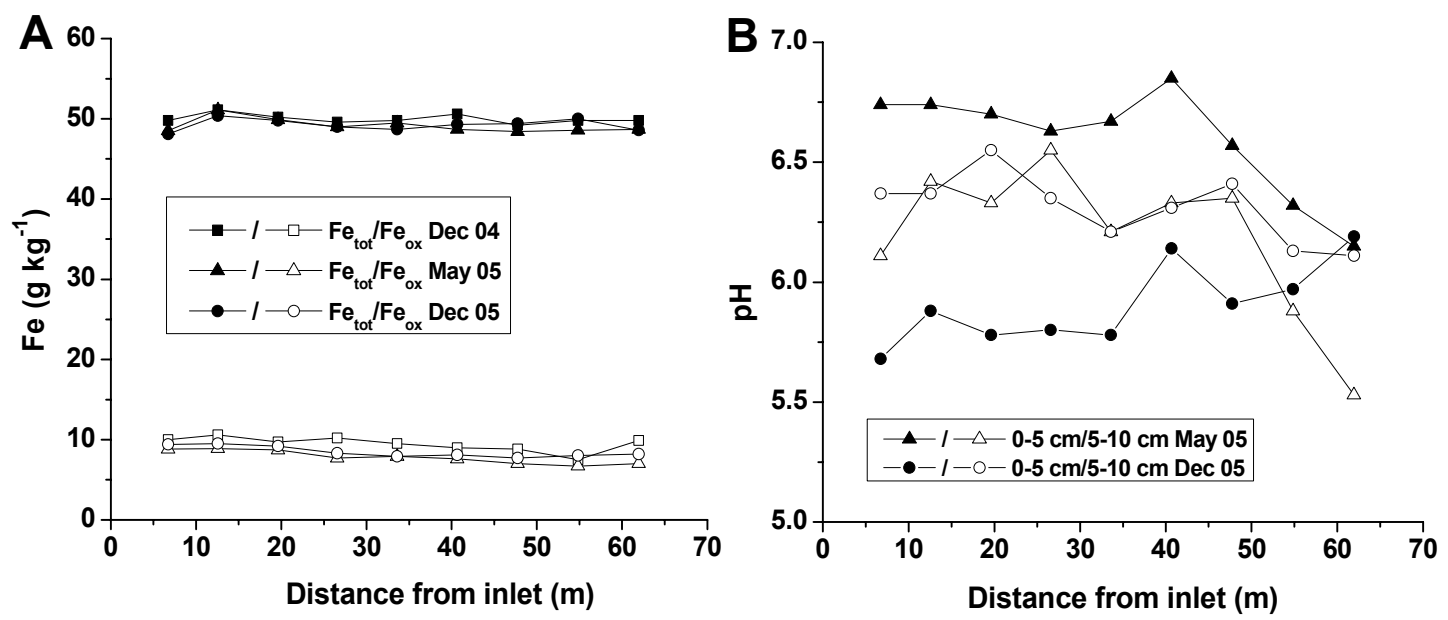

FIGURE S3: (A) Total and oxalate extractable Fe concentrations of topsoil $(0-10 \mathrm{~cm})$ sampled along a transect from the water inlet $(x=0 \mathrm{~m})$ to the opposite corner of field I (see Figs. 1 and 3) in December 2004, May 2005 and December 2005. (B) pH in the topsoil $(0-5 / 5-10 \mathrm{~cm})$ in May and December 2005. The RSD of the measurements was $<7 \%$ for total and $<5.5 \%$ for oxalate extractable concentrations.

\subsection{Total As in soil versus total As in irrigation water}

Figure S4 shows total As concentrations in soil (0-5 cm, May 2005) versus total As concentrations in irrigation water on field I directly after irrigation (April 2005). As concentrations in the water, and consequently As input to soil, decrease with distance from the inlet, resulting in a close correlation between soil and irrigation water As contents measured at different distances from the irrigation water inlet. 


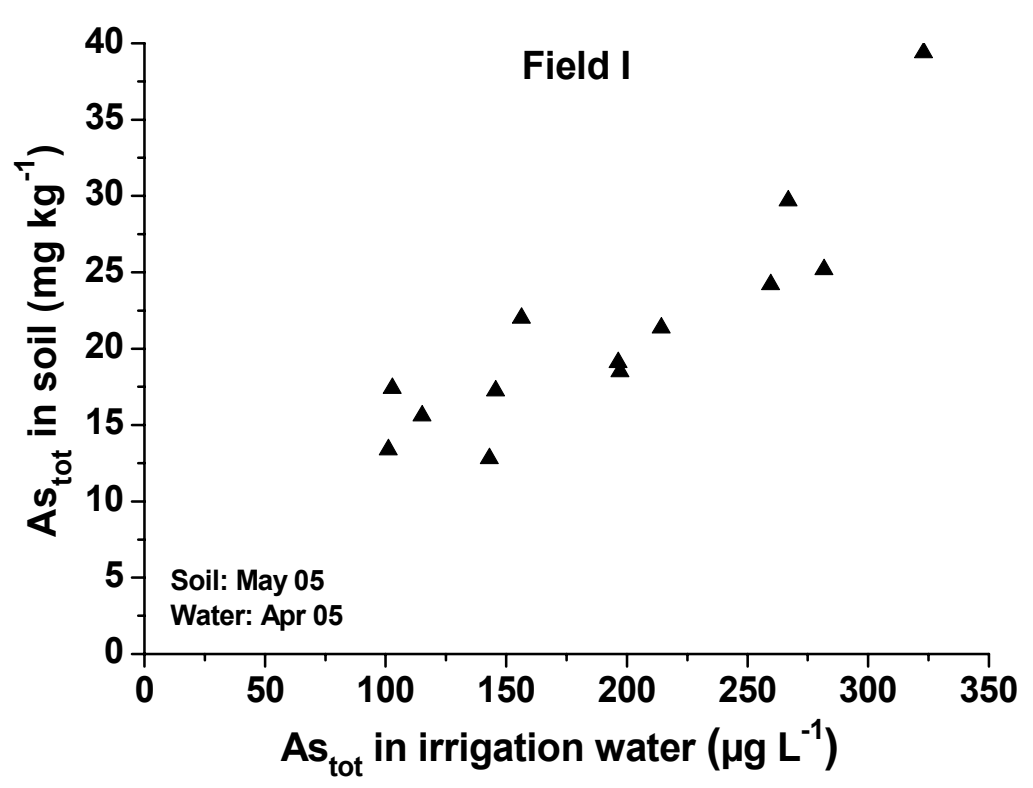

FIGURE S4: Total soil As in $0-5 \mathrm{~cm}$ depth (May 2005) versus total As (unfiltered) in irrigation water (April 2005) in field I $(n=13)$. Irrigation took place from 7-10 am and water was sampled from 10:20-12:30 am, as described in (4). Figure 1 in the main part and Figure 1 of the companion manuscript (4) indicate soil and water sampling locations, respectively. Each water sampling point was correlated to the nearest soil sampling point (maximum distance between the points: $6.9 \mathrm{~m} ; \mathrm{n}=10$ ). For water sampling points lying between two soil sampling points, the average As concentration of the two soil samples was plotted (maximum distance between water sampling point and virtual soil sampling point: $4.1 \mathrm{~m} ; \mathrm{n}=3$ ).

\subsection{Total topsoil As concentrations at all sampling points}

Figure S5 depicts total topsoil $(0-10 \mathrm{~cm})$ As concentrations for all sampling points in field I from December 2004, May 2005, and December 2005 as a function of distance from the irrigation inlet. The data confirm the trends observed along the transect (main manuscript, Figure 2A): From December 2004 to May 2005, an increase in topsoil As contents is observed, which decreases with increasing distance from the irrigation inlet. After the monsoon in December 2005, topsoil As concentrations are again lower, especially close to the inlet where most input occurred during irrigation. 

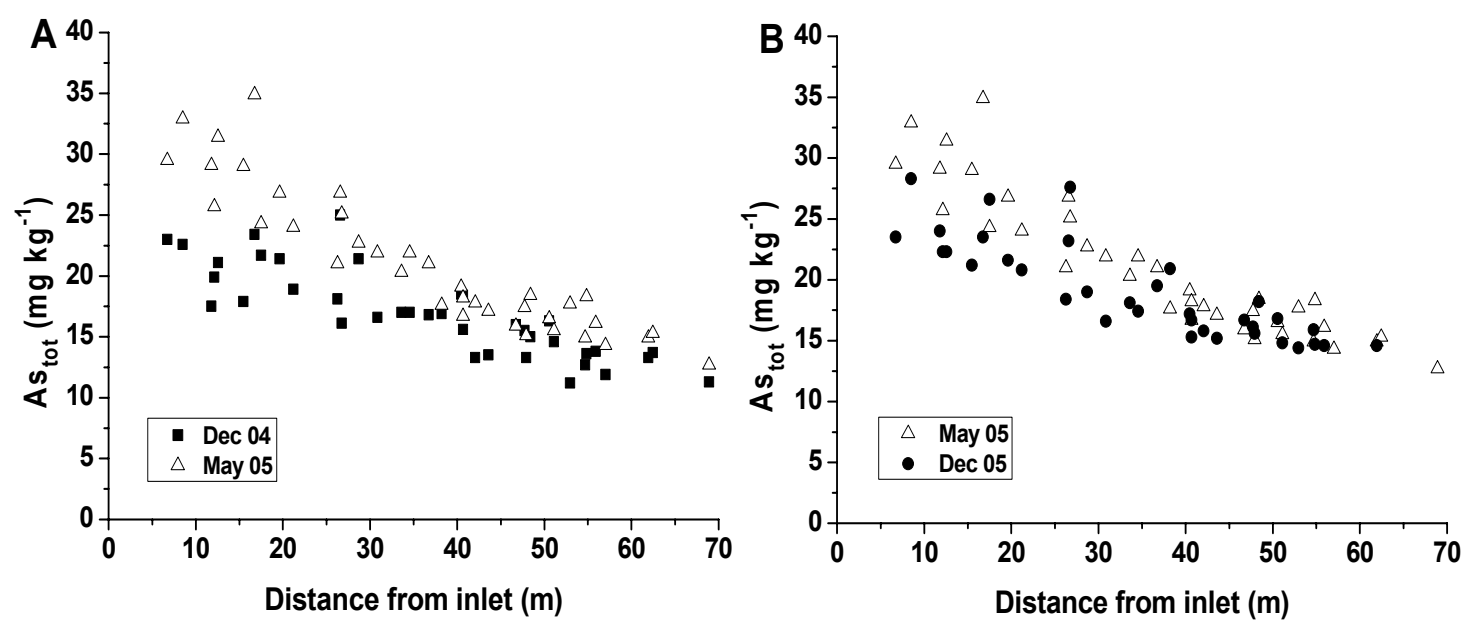

FIGURE S5: Total As concentrations of topsoil $(0-10 \mathrm{~cm})$ sampled in Field I with increasing distance from the water inlet $(x=0$ m). (A) December $2004(n=38)$ and May $2005(n=38)$. (B) May 2005 and December $2005(n=35)$.

\subsection{Total subsoil As and $P$ along transect}

Figure S6 shows the total As and P concentrations profiles in the subsoil $(25 / 30-40 \mathrm{~cm})$ of field I along the transect (see Figs. 1 and 3). Except for the sampling point nearest to the inlet, As concentrations in the subsoil do not increase from December 2004 to May 2005.
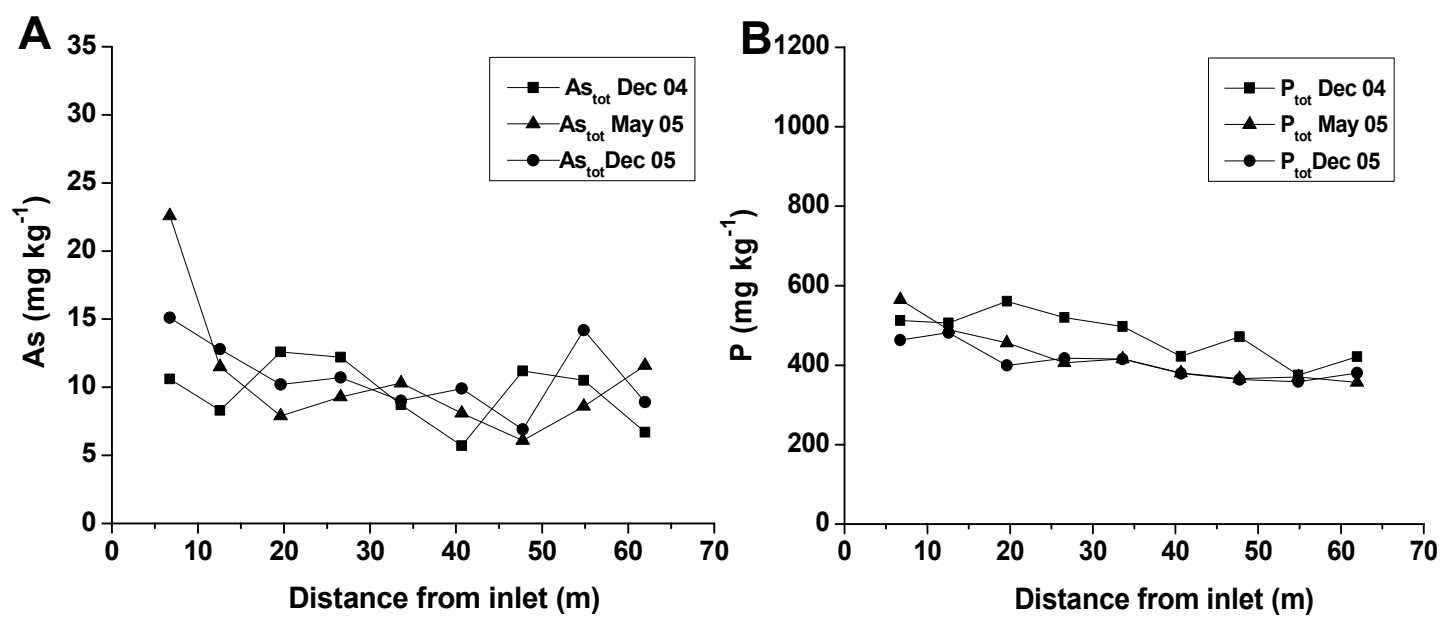

FIGURE S6: Total As $(A)$ and $P(B)$ concentrations of subsoil $(25 / 30-40 \mathrm{~cm})$ sampled along a transect from the water inlet $(x=0 \mathrm{~m})$ to the opposite corner of field I (see Figs. 1 and 3 ) in December 2004, May 2005 and December 2005. 


\section{References}

(1) McKeague, J. A.; Day, D. H. Dithionite- and oxalate-extractable Fe and Al as aids in differentiating various classes of soils. Can. J. Soil Sci. 1966, 46, 13-22.

(2) WRB, I. W. G. World reference base for soil resources 2006 - A framework for international classification, correlation and communication; Food and Agriculture Organization of the United Nations: Rome, 2006.

(3) Brammer, H. The Geography of the Soils of Bangladesh; University Press Limited: Dhaka, 1996.

(4) Roberts, L. C.; Hug, S. J.; Dittmar, J.; Voegelin, A.; Kretzschmar, R.; Saha, G. C.; Ali, M. A.; Badruzzaman, A. B. M. Spatial distribution and temporal variability of arsenic in irrigated rice fields in Bangladesh: 1. Irrigation water. Environ. Sci. Technol. 2007, 41 (companion article). 